\title{
Crescimento do capim-tifton 85 sob doses de nitrogênio e alturas de corte ${ }^{1}$
}

\author{
Odilon Gomes Pereira ${ }^{2}$, Rivelino Rovetta ${ }^{3}$, Karina Guimarães Ribeiro ${ }^{4}$, Manoel Eduardo \\ Rozalino Santos ${ }^{5}$, Dilermando Miranda da Fonseca ${ }^{2}$, Paulo Roberto Cecon ${ }^{6}$
}

\author{
${ }^{1}$ Research supported by FAPEMIG. \\ 2 Departamento de Zootecnia da Universidade Federal de Viçosa. \\ ${ }^{3}$ Centro Universitário de Vila Velha. \\ ${ }^{4}$ Departamento de Zootecnia da Universidade Federal dos Vale do Jequitinhonha e Mucuri. \\ 5 Pós-doutorado do Programa de Pós-graduação em Zootecnia da Universidade Federal de Viçosa. \\ ${ }^{6}$ Departamento de Informática da Universidade Federal de Viçosa.
}

RESUMO - Objetivou-se avaliar os índices de crescimento do capim-tifton 85 adubado com quatro doses de nitrogênio $(0,33,66,100$, e $133 \mathrm{~kg} /$ ha de $\mathrm{N})$ e colhido em três alturas da planta (30, 40 e $50 \mathrm{~cm})$. O delineamento experimental utilizado foi inteiramente casualizado em esquema de parcelas subdivididas com três repetições. As doses de nitrogênio corresponderam às parcelas e as alturas na data de corte, às subparcelas. Para todas as variáveis analisadas, a interação dose de $\mathrm{N} \times$ altura da planta não foi significativa. A taxa assimilatória líquida e a taxa de crescimento relativo do capim-tifton 85 aumentaram com as doses de nitrogênio. A razão de área foliar (RAF) decresceu linearmente com a altura de corte das plantas, mas aumentou, também de forma linear, com a dose de nitrogênio. De modo linear, a razão de peso foliar decresceu com a altura de corte da planta forrageira e aumentou com a dose de nitrogênio. A área foliar específica do capim-tifton 85 foi influenciada de forma linear e positiva apenas pela adubação nitrogenada. O índice de área foliar (IAF) do capim-tifton 85 aumentou cerca de 0,05 unidade a cada centímetro de incremento na altura de corte das plantas. Houve resposta quadrática da dose de nitrogênio no IAF do capim-tifton 85. O acréscimo na altura do capim-tifton 85 na época do corte reduz a participação de lâmina foliar na forragem. A adubação nitrogenada aumenta a taxa de crescimento do capim-tifton 85, portanto, para assegurar colheita eficiente da forragem, ao aumentar a dose de nitrogênio, é necessário reduzir o intervalo de colheita.

Palavras-chave: Cynodon, frequência de corte, índice de área foliar, lâmina foliar

\section{Growth analysis of Tifton 85 bermudagrass under nitrogen fertilization and plant height}

\begin{abstract}
The objective this study was to evaluate the growth rates of Tifton 85 bermudagrass under four nitrogen levels $(0,33,66,100$, and $133 \mathrm{~kg} / \mathrm{ha} \mathrm{N})$ and harvested at three plant heights (30, 40 and $50 \mathrm{~cm})$. The experimental design was completely randomized in a split plot scheme with three replications. Nitrogen rates were set in the plots and plants heights in the subplots. For all variables, the interaction $\mathrm{N}$ rate $\times$ plant height was not significant. The net assimilatory rate and relative growth rate of Tifton 85 increased with increasing $\mathrm{N}$ rates. The leaf area ratio (LAR) decreased linearly with plant height at harvesting. In contrast, the LAR increased linearly with $\mathrm{N}$ rate. Linearly, the leaf weight ratio decreased with plant height at harvesting, and increased with $\mathrm{N}$ rate. The specific leaf area of Tifton 85 bermudagrass was influenced linear and positively only by nitrogen fertilization. The leaf area index (LAI) of Tifton 85 bermudagrass increased by about 0.05 unit for each centimeter increase in plant height at harvesting. There was a quadratic response of $\mathrm{N}$ in LAI of Tifton 85 bermudagrass. The increase of bermudagrass height at harvesting season decreases the participation of leaf blade in the forage. The nitrogen increases the growth rate of Tifton 85 bermudagrass. To ensure efficient harvesting of forage, the increase of $\mathrm{N}$ rate for Tifton 85 Bermudagrass implies a reduction in the harvest interval.
\end{abstract}

Key Words: Cynodon, frequency cut, leaf area index, leaf blade

\section{Introdução}

O capim-tifton 85 é um híbrido do gênero Cynodon oriundo do cruzamento do cultivar tifton 68 com uma introdução PI-290884, proveniente da África do Sul (Burton et al., 1967). Esta planta forrageira é perene, estolonífera, rizomatoza e possui elevado potencial de produção de forragem com qualidade (Pedreira, 2010).

Para se obter máxima produtividade do capim-tifton 85, é importante compreender seu crescimento em diversas condições de manejo. Nesse sentido, o estudo da análise de crescimento permite conhecer as mudanças na morfologia 
da planta que ocorrem com o tempo e identificar as características da planta determinantes de sua produtividade e adaptação ao ambiente (Lambers, 1987).

As principais características de crescimento das plantas são: taxa de crescimento cultural; taxa de crescimento relativo; taxa assimilatória líquida; razão de área foliar, que se decompõe em área foliar específica e razão de peso foliar; índice de área foliar e duração de área foliar (Radford, 1967; Benincasa, 2003). Essas características são modificadas pela adubação nitrogenada (Paciullo et al., 1998) e pela altura da planta na época da colheita (Limão, 2010), ações que têm grande impacto na produtividade da pastagem.

A fertilização nitrogenada incrementa a produtividade da pastagem, pois, em geral, o nitrogênio melhora o fluxo de tecidos em gramíneas tropicais (Martuscello et al., 2005; Fagundes et al., 2006), o que favorece a taxa de crescimento cultural, pela rápida restauração da área foliar e pelo aumento da taxa assimilatória líquida (Paciullo et al., 1998).

As mudanças causadas pela adubação nitrogenada no crescimento da planta forrageira geram a necessidade de ajustes no manejo da desfolhação para garantir eficiência de colheita da forragem (Fonseca et al., 2008). O ajuste no manejo da desfolhação pode ser realizado com base na altura do pasto na época de colheita, o que irá determinar a frequência da desfolhação. O emprego da altura do pasto como critério do manejo da desfolhação é vantajoso pela sua alta associação com a interceptação de luz pelo dossel (Barbosa et al., 2007) e com a estrutura do pasto (Carvalho et al., 2001), além de sua praticidade de utilização (Carnevalli, 2009).

Dessa forma, foram avaliados os efeitos da adubação nitrogenada e da altura da planta na época de corte nos índices de crescimento do capim-tifton 85 cultivado na Zona da Mata de Minas Gerais, a fim de gerar informações que auxiliem na idealização de estratégias de manejo para essa planta forrageira.

\section{Material e Métodos}

O experimento foi conduzido de novembro 1998 a fevereiro de 1999 numa área estabelecida com capim-tifton 85 (Cynodon spp.), pertencente ao Departamento de Zootecnia da Universidade Federal de Viçosa, na cidade de
Viçosa, Minas Gerais, localizada na Zona da Mata mineira, à altitude de $651 \mathrm{~m}$, latidude sul de $20^{\circ} 45^{\prime}$ e longitude oeste de $42^{\circ} 51^{\prime}$.

O capim-tifton 85 foi estabelecido na área experimental pelo plantio em sulcos, com $15 \mathrm{~cm}$ de profundidade e espaçados a cada $50 \mathrm{~cm}$. No período de novembro de 1996 a junho de 1997, antes da implantação deste experimento, a área foi utilizada em trabalho de pesquisa com o objetivo de avaliar o rendimento forrageiro e o valor nutritivo do capimtifton 85 adubado com cinco doses de nitrogênio $(0,100$, 200, 300 e $400 \mathrm{~kg} / \mathrm{ha} / \mathrm{ano}$ ), aplicadas na forma de ureia, e colhido em três idades de rebrotação (28, 42 e 56 dias).

O solo da área experimental é classificado como argissolo vermelho-amarelo, com textura argilo-arenosa. Os atributos químicos do solo foram determinados no início de outubro de 1998, na camada 0-20 cm de profundidade, os quais apresentaram os seguintes resultados: $\mathrm{pH}$ em $\mathrm{H}_{2} \mathrm{O}$ : 5,8; P disponível: 9,8 (Mehlich-1) e K disponível: $45,2 \mathrm{mg} \cdot \mathrm{dm}^{-3} ; \mathrm{Ca}^{2+}: 2,9 ; \mathrm{Mg}^{2+}: 0,4 \mathrm{e} \mathrm{Al}^{3+}: 0,1 \mathrm{cmol}_{\mathrm{C}} \cdot \mathrm{dm}^{-3}$ (KCl $1 \mathrm{~mol} / \mathrm{L}$ ); e saturação por bases: 50,5\%.

Durante o período de avaliação, os dados climáticos foram registrados em estação meteorológica do Departamento de Engenharia Agrícola da Universidade Federal de Viçosa (Tabela 1).

Foram avaliadas cinco doses de nitrogênio (0, 33, 66, 100 , e $133 \mathrm{~kg} / \mathrm{ha} /$ corte de N), usando-se como fonte a ureia, e três alturas ao tempo de corte (30, 40 e $50 \mathrm{~cm})$. Devido à uniformidade das características do solo, do relevo e do histórico de uso da pastagem de capim-tifton 85, o delineamento experimental utilizado foi inteiramente casualizado em esquema de parcelas subdivididas, com três repetições. As doses de nitrogênio corresponderam às parcelas e as alturas ao tempo de corte, às subparcelas. As parcelas mediram $36 \mathrm{~m}^{2}(3,0 \times 12,0 \mathrm{~m})$ e as subparcelas, $12 \mathrm{~m}^{2}$ $(3,0 \times 4,0 \mathrm{~m})$.

Para evitar a ocorrência de viés, devido ao efeito residual da adubação nitrogenada realizada em experimento prévio (novembro de 1996 a junho de 1997), as doses de nitrogênio e as parcelas experimentais deste trabalho foram similares às do experimento anterior. Todavia, no experimento anterior, o fator doses de nitrogênio (0, 100, 200, 300 e $400 \mathrm{~kg} / \mathrm{ha})$ foi avaliado em três aplicações, cada uma correspondente a

Tabela 1 - Temperaturas máxima e mínima, precipitação pluvial total e umidade relativa média do ar durante o período experimental

\begin{tabular}{|c|c|c|c|c|c|}
\hline \multirow[t]{2}{*}{ Mês } & \multirow[t]{2}{*}{ Ano } & \multicolumn{2}{|c|}{ Temperatura $\left({ }^{\circ} \mathrm{C}\right)$} & \multirow[t]{2}{*}{ Precipitação (mm) } & \multirow[t]{2}{*}{ Umidade (\% } \\
\hline & & Máxima & Mínima & & \\
\hline Novembro & 1998 & 26,0 & 16,9 & 216,9 & 84,7 \\
\hline Dezembro & 1998 & 28,8 & 18,3 & 105,3 & 82,5 \\
\hline Janeiro & 1999 & 30,3 & 18,9 & 154,2 & 78,2 \\
\hline Fevereiro & 1999 & 29,9 & 18,4 & 88,1 & 78,1 \\
\hline
\end{tabular}


0, 33, 66, 100, e $133 \mathrm{~kg} /$ ha.corte de N. Neste experimento, as doses de nitrogênio foram expressas em $\mathrm{kg} / \mathrm{ha} /$ corte $(0,33$, 66,100 , e $133 \mathrm{~kg} / \mathrm{ha} /$ corte de N), pois as avaliações de análise de crescimento ocorreram apenas no primeiro corte, época em que os efeitos das doses de nitrogênio foram ocasionados pelo fato de que uma única aplicação foi realizada antes do primeiro corte.

Após o corte de uniformização, efetuaram-se a calagem e as adubações nitrogenada e potássica. Para a calagem, usou-se o calcário calcítico para elevar a saturação por bases de $50,5 \%$ para $60 \%$ em todas as parcelas. Com a adubação potássica, objetivou-se elevar a disponibilidade de potássio para $100 \mathrm{mg} / \mathrm{dm}^{3}$ (Cantarutti et al., 1999), usando o cloreto de potássio. A adubação nitrogenada referente a cada tratamento foi aplicada na forma de ureia.

As variáveis de crescimento foram avaliadas apenas durante um único corte, em datas que variaram de acordo com as doses de nitrogênio (Tabela 2). Na segunda semana após o corte de uniformização, o desenvolvimento do capimtifton 85 foi monitorado por mensurações da altura das plantas a cada três dias até que as mesmas alcançassem as alturas preestabelecidas nos tratamentos. O critério para medição da altura das plantas correspondeu à distância do nível do solo até o horizonte superior das folhas no dossel.

Um único corte foi realizado em cada parcela, colhendose a forragem presente em $1,0 \mathrm{~m}^{2}$ de área útil, a $5 \mathrm{~cm}$ da superfície do solo. A forragem colhida foi pesada e, posteriormente, uma subamostra foi colocada em saco plástico identificado e levada ao laboratório, onde a fração lâmina foliar foi separada, acondicionada em sacos de papel e submetida à secagem em estufa de ventilação forçada a $65^{\circ} \mathrm{C}$ por 72 horas.

Tabela 2 - Datas dos cortes e idade do capim-tifton 85 adubado com cinco doses de nitrogênio e três alturas durante dezembro de 1998 a fevereiro de 1999

\begin{tabular}{lccc}
\hline Data de corte & Idade (dia) & Altura $(\mathrm{cm})$ & Nitrogênio $(\mathrm{kg} / \mathrm{ha})$ \\
\hline $21 / 11 / 98$ & & Corte de uniformização & \\
$16 / 12 / 98$ & 25 & 30 & 133 \\
$21 / 12 / 98$ & 30 & 40 & 133 \\
$21 / 12 / 98$ & 30 & 30 & 100 \\
$23 / 12 / 98$ & 32 & 50 & 133 \\
$29 / 12 / 98$ & 38 & 40 & 100 \\
$29 / 12 / 98$ & 38 & 30 & 66 \\
$05 / 01 / 99$ & 44 & 40 & 66 \\
$05 / 01 / 99$ & 44 & 50 & 100 \\
$07 / 01 / 99$ & 46 & 50 & 66 \\
$07 / 01 / 99$ & 46 & 30 & 33 \\
$15 / 01 / 99$ & 54 & 40 & 33 \\
$22 / 01 / 99$ & 61 & 30 & 0 \\
$11 / 02 / 99$ & 81 & 50 & 33 \\
$18 / 02 / 99$ & 88 & 40 & 0 \\
$18 / 02 / 99$ & 88 & 50 & 0 \\
\hline
\end{tabular}

As medições de área laminar foram realizadas em aparelho medidor de área (Sistema de Análise de Imagem, Delta - T) utilizando-se 20 perfilhos colhidos em cada parcela. Depois, cada amostra de lâmina foliar foi colocada em saco de papel e mantida em estufa de ventilação forçada a $65^{\circ} \mathrm{C}$ por 72 horas para determinação da massa seca. A estimativa da área foliar total das lâminas foliares verdes presentes na área útil de $1,0 \mathrm{~m}^{2}$ foi obtida multiplicando-se a massa de lâmina foliar (em 1,0 $\mathrm{m}^{2}$ ) pela área foliar de 20 perfilhos e dividindo o produto pela massa de lâmina foliar seca dos 20 perfilhos. Oíndice deárea foliar foi determinado pelo quociente da área foliar pela área de solo (no caso, em 1,0 m²).

A taxa assimilatória líquida (g.m $\left.{ }^{-2} \cdot \operatorname{dia}^{-1}\right)$, taxa de crescimento relativo $\left(\mathrm{g} \cdot \mathrm{g}^{-1} \cdot \mathrm{dia}^{-1}\right)$, a razão de área foliar $\left(\mathrm{m}^{2} \cdot \mathrm{g}^{-1}\right)$, a área foliar específica $\left(\mathrm{m}^{2} \cdot \mathrm{g}^{-1}\right)$ e a razão de peso foliar (g.g ${ }^{-1}$ ) foram calculadas segundo Benincasa (2003).

As análises dos resultados experimentais foram feitas usando o SAEG (Sistema de Análises Estatísticas e Genéticas, versão 8.1). Para as variáveis mensuradas pontualmente, índice de área foliar, razão de área foliar, área foliar específica e razão de peso foliar, foram realizadas análises de variância (ANOVA) e de regressão, cujo maior modelo de superfície de resposta em função das médias dos fatores em estudo foi o seguinte:

$Y_{i}=\beta_{0}+\beta_{1} N_{i}+\beta_{2} N_{i}^{2}+\beta_{3} A_{i}+\beta_{4} N_{i} A_{i}+e_{i}$ em que: $Y_{i}=$ variável-resposta; $N_{i}=$ dose de nitrogênio; $A_{i}=$ altura da planta; $\beta_{0}, \beta_{1}, \beta_{2}, \beta_{3}, \beta_{4}=$ parâmetros a ser estimados; $\mathrm{e}_{\mathrm{i}}=$ erro experimental.

Para as taxas assimilatória líquida e de crescimento relativo, cujas medidas não podem ser realizadas pontualmente e, portanto, necessitam de avaliação durante um período (Benincasa, 2003), consideraram-se dois intervalos de tempo: um correspondente ao crescimento do capim-tifton 85 de 30 até $40 \mathrm{~cm}$, e outro referente ao crescimento da planta de 40 até $50 \mathrm{~cm}$ de altura. Desse modo, avaliaram-se os efeitos da dose de nitrogênio dentro de cada intercalo de tempo pelas análises de variância (ANOVA) e de regressão, cujo modelo linear foi o que melhor se ajustou aos dados.

O grau de ajustamento dos modelos foi avaliado pelo coeficiente de determinação e pela significância dos coeficientes de regressão, testada pelo teste t corrigido com base nos resíduos da análise de variância. Todas as análises estatísticas foram realizadas ao nível de até $10 \%$ de probabilidade de ocorrência do erro tipo I.

\section{Resultados e Discussão}

Não foi significativa a interação dose de nitrogênio × intervalo de crescimento na taxa assimilatória líquida 
(TAL) do capim-tifton 85. A taxa assimilatória líquida foi maior quando o capim-tifton 85 cresceu de 30 para $40 \mathrm{~cm}$ $(5,91 \mathrm{~g} / \mathrm{m} / \mathrm{dia})$ em comparação ao intervalo de crescimento de 40 para $50 \mathrm{~cm}$ (5,26 g/m/dia). A taxa assimilatória líquida também incrementou linearmente com o aumento das doses de nitrogênio no intervalo de crescimento de 30 até $40 \mathrm{~cm}$ $\left(\hat{Y}=3,4748+0,0269 * N ; R^{2}=0,94 ; P \leq 0,10\right)$ e de 40 até $50 \mathrm{~cm}$ $\left(\hat{Y}=3,5737+0,0352 * N ; R^{2}=0,95 ; P \leq 0,10\right)$.

$\mathrm{O}$ aumento da taxa assimilatória líquida com o incremento das doses de nitrogênio pode ser explicado pelo menor tempo que o capim-tifton 85 gastou para atingir as alturas de corte preestabelecidas quando adubado com doses mais elevadas de nitrogênio. Com o emprego de doses maiores de nitrogênio (100 e 133 kg/ha/corte), a planta forrageira foi colhida com aproximadamente 25 e 28 dias de idade, respectivamente. A adubação com doses de 0 e $33 \mathrm{~kg} / \mathrm{ha} /$ corte de nitrogênio possibilitou cortes da planta forrageira a partir dos 46 dias de crescimento. Dessa forma, para uma mesma altura de corte, plantas sob maiores doses de nitrogênio apresentaram menor idade à colheita, o que pode justificar sua maior taxa assimilatória líquida (Freitas, 2009).

Outro fator que também pode ter contribuído com os menores valores para a taxa assimilatória líquida do capimtifton 85 sob doses mais baixas de nitrogênio foi a maior senescência foliar nessas condições. De fato, a senescência foliar, assim como a clorose foliar mais intensa nas folhas mais velhas, é um sintoma de deficiência de nitrogênio para a planta (Marenco \& Lopes, 2009).

Além disso, o nitrogênio influencia positivamente a eficiência fotossintética da folha por estimular a síntese de rubisco (Chapin et al., 1987), enzima chave nas reações bioquímicas de assimilação do carbono.

Por outro lado, a menor taxa assimilatória líquida predominante no intervalo de tempo em que o capim-tifton 85 cresceu de 40 até $50 \mathrm{~cm}$, em comparação ao de 30 até $40 \mathrm{~cm}$, pode ter sido resultado do sombreamento mais acentuado das folhas inferiores em pastos com maior altura, o que, possivelmente, diminui sua eficiência fotossintética. Um período de crescimento longo, caracterizado pela colheita de plantas mais altas, compromete a produção líquida de forragem, devido à intensificação, tanto das perdas por senescência quanto das perdas respiratórias de carbono (Parsons et al., 1983).

Para a taxa de crescimento relativo, também não houve significância da interação doses de nitrogênio × intervalos de crescimento. A taxa de crescimento relativo do capimtifton 85 não diferiu quando as plantas cresceram de 30 até $40 \mathrm{~cm}$ ou de 40 até $50 \mathrm{~cm}$, apresentando valor médio de
0,044 g/g/dia. Contudo, em ambos os intervalos de crescimento, aumentou linearmente com o acréscimo das doses de nitrogênio $\left(\hat{Y}=0,0132+0,0005^{* * *} \mathrm{~N} ; \mathrm{R}^{2}=0,97\right.$; $\mathrm{P} \leq 0,01)$. Os valores de taxa de crescimento relativo corroboram aqueles encontrados por Oliveira et al. (2000), que registraram valores de 0,12 a $0,026 \mathrm{~g} / \mathrm{g} /$ dia para o capimtifton 85 sob idades de rebrotação.

Conforme já relatado, o aumento na taxa de crescimento relativo com a dose de nitrogênio pode ser explicado pelo menor tempo que o nitrogênio proporcionou para que as plantas atingissem as alturas de corte preestabelecidas. Desse modo, plantas forrageiras mais jovens têm maior capacidade fotossintética e, consequentemente, maior taxa de crescimento relativo. Por outro lado, à medida que as plantas envelhecem, ocorrem redução na capacidade fotossintética e início da senescência das folhas, diminuindo a eficiência fotossintética e sua taxa de crescimento relativo.

Para a razão de área foliar do capim-tifton 85, não houve significância para a interação doses de nitrogênio × alturas de corte. Contudo, de forma linear, seus valores decresceram com o aumento da altura de corte das plantas e aumentaram com a adubação, de acordo com o modelo $\hat{Y}=0,00869$ $0,0001010^{* * *} \mathrm{~A}+0,000045^{* * *} \mathrm{~N}\left(\mathrm{P} \leq 0,01, \mathrm{R}^{2}=0,86\right)$.

O aumento da razão de área foliar do capim-tifton 85 com o incremento das doses de nitrogênio deve-se ao efeito do nutriente no crescimento mais rápido do capim, que atinge altura de corte em idade mais jovem, situação na qual pode ocorrer maior percentual de folhas na planta forrageira (Santos et al., 2009). Adicionalmente, altas doses de nitrogênio resultam em maiores taxas de alongamento de folhas (Martuscello et al., 2005; Fagundes et al., 2006), variáveis que influenciam positivamente no tamanho das folhas e, consequentemente, na razão de área foliar da planta.

De outro modo, a redução na razão de área foliar do capim-tifton 85 com a altura da planta na época de corte indica que maior alocação de fotoassimilados foi destinada para o colmo e os tecidos reprodutivos em detrimento às folhas (Benincasa, 2003).

As alterações na razão de área foliar do capim-tifton 85 estão relacionadas a modificações em outros índices de crescimento, como a razão de peso foliar e a área foliar específica (Gomide \& Gomide, 1999). A razão de peso foliar foi influenciada independentemente pelos fatores estudados, decrescendo de forma linear com o aumento da altura de corte da planta e aumentando linearmente com a dose de nitrogênio ( $\hat{\mathrm{Y}}=0,610521-0,00468^{* * *} \mathrm{~A}+0,000548 * * * \mathrm{~N}$ $\left(\mathrm{P} \leq 0,01, \mathrm{R}^{2}=0,56\right)$. Desse modo, estimaram-se valores de razão de peso foliar correspondentes a 0,44 e 0,54; 0,42 e 0,50 ; e 0,38 e $0,45 \mathrm{~g} / \mathrm{g}$ para plantas colhidas ao atingirem 
30, 40 e $50 \mathrm{~cm}$ de altura nas doses de 0 e $133 \mathrm{~kg} / \mathrm{ha} /$ corte de $\mathrm{N}$, respectivamente.

A redução na razão de peso foliar em plantas com maior altura e idade ocorreu provavelmente devido à maior translocação de fotoassimilados para produção de colmo em plantas mais altas. Esse argumento encontra respaldo no trabalho desenvolvido por Oliveira et al. (2000), que avaliaram o capim-tifton 85 desde 14 até 70 dias de rebrotação e verificaram que a relação folha/colmo dessa forrageira reduziu, apresentando razão de peso foliar de 0,59 a $0,27 \mathrm{~g} / \mathrm{g}$, respectivamente.

O aumento da razão de peso foliar do capim-tifton 85 decorrente da adubação nitrogenada pode ser atribuído ao crescimento mais rápido, somado às maiores taxas de aparecimento e alongamento de folhas normalmente verificadas em situações em que maiores doses de nitrogênio são utilizadas (Martuscello et al., 2005; Fagundes et al., 2006).

A diminuição dos valores de razão de área foliar e razão de peso foliar com a elevação da altura do capim-tifton 85 na época de corte permite inferir que há redução no percentual de folha no pasto. Com isso, pode haver comprometimento do valor nutritivo e da estrutura do pasto (Santos et al., 2009). Nesse sentido, a colheita do capim-tifton 85 com altura inferior à avaliada neste trabalho $(30 \mathrm{~cm})$ constituiria, possivelmente, ação de manejo que possibilitaria a produção de forragem com características predisponentes ao maior desempenho animal, conforme sugerido por Pedreira \& Tonato (2006). Contudo, ressalta-se a necessidade de testar essa hipótese com base na experimentação científica.

Não foi significativa a interação doses de nitrogênio $\times$ alturas de corte para a área foliar específica do capim-tifton, que também não foi influenciada pela altura da planta na época do corte, de modo que ocorreu efeito apenas da adubação nitrogenada nessa característica, que aumentou linearmente com a dose de nitrogênio, segundo a equação $\hat{Y}=0,011395+0,00007555^{* *} \mathrm{~N}\left(\mathrm{P} \leq 0,05 ; \mathrm{R}^{2}=0,95\right)$.

$\mathrm{O}$ aumento da área foliar específica com a adubação nitrogenada está relacionado à menor espessura da lâmina foliar em doses elevadas de nitrogênio. Em condições de maior quantidade de nitrogênio no interior da planta, a lignificação da folha tende a ser menor (Alves, 2000), o que contribui para aumentar a área foliar por unidade de peso da folha.

O índice de área foliar do capim-tifton 85 não foi influenciado pela interação doses de nitrogênio $\times$ alturas de corte. Contudo, aumentou linearmente com a altura de corte das plantas. A adubação nitrogenada, no entanto, teve efeito quadrático no índice de área foliar, cujos valores máximos foram estimados em 4,49; 4,96; e 5,43 para a dose de $133,0 \mathrm{~kg} / \mathrm{ha} / \mathrm{corte}$ de $\mathrm{N}$ nas plantas colhidas ao atingirem 30, 40 e $50 \mathrm{~cm}$ de altura, respectivamente. O modelo que melhor se ajustou aos dados de índice de área foliar em função dos fatores avaliados foi $\hat{\mathrm{Y}}=-0,505378+$ $0,0473315 * * * A+0,054069 * * * N-0,000204336 * * * N^{2}$ $\left(\mathrm{P} \leq 0,01, \mathrm{R}^{2}=0,97\right)$.

Provavelmente, o aumento do índice de área foliar em plantas mais altas de capim-tifton 85 esteve relacionado ao aumento no número de folhas vivas até certa idade (Garcez Neto et al., 2002), bem como ao maior tamanho das lâminas foliares com o avanço da maturidade das plantas (Oliveira et al., 2000).

O aumento do índice de área foliar com o aumento da dose de nitrogênio deve-se, provavelmente, às maiores taxas de aparecimento e alongamento de folhas. Além disso, o nitrogênio proporciona aumentos no comprimento das lâminas foliares (Garcez Neto et al., 2002) e resulta em maiores valores de índice de área foliar na planta forrageira (Martuscello et al., 2005; Fagundes et al., 2006).

O nitrogênio incrementou os índices de crescimento do capim-tifton 85, ou seja, aumentou o crescimento da planta forrageira por unidade de tempo. Em mesma altura de planta na época do corte, as maiores doses de nitrogênio viabilizaram a colheita do capim-tifton 85 em menores intervalos de rebrotação (Tabela 2). Esse fato comprova que o uso de adubos nitrogenados nas pastagens exige a adoção de períodos de descanso mais curtos ou o emprego de maiores frequências de pastejo, a fim de garantir a colheita de forragem com eficiência sem prejudicar a estrutura e o valor nutritivo do pasto (Fonseca et al., 2008).

\section{Conclusões}

O aumento da altura do capim-tifton 85 na época do corte reduz a taxa assimilatória líquida e a participação de lâmina foliar na forragem produzida. A adubação nitrogenada melhora os índices de crescimento e, por conseguinte, a taxa de crescimento do capim-tifton 85. Para assegurar a colheita eficiente da forragem, o aumento da dose de nitrogênio implica reduzir o intervalo de colheita do capim-tifton 85.

\section{Referências}

ALVES, M.J. Rendimento forrageiro e valor nutritivo do capim-tifton 85 (Cynodon spp) sob diferentes doses de nitrogênio, colhido ao atingir 30,40 e $50 \mathrm{~cm}$ de altura. 2000. 52f. Dissertação (Mestrado em Zootecnia) - Universidade Federal de Viçosa, Viçosa, MG.

BARBOSA, R.A.; NASCIMENTO JÚNIOR, D.; EUCLIDES, V.P.B. et al. Características estruturais e produção de forragem do 
capim-tanzânia submetido à combinação entre intensidade e frequência de pastejo. Pesquisa Agropecuária Brasileira, v.42, n.3, p.329-340, 2007.

BENINCASA, M.M.P. Análise de crescimento de plantas: noções básicas. Jaboticabal: FUNEP, 2003. 41p.

BURTON, G.W.; HART, R.H.; LOWREY, R.S. Improving forage quality by breeding. Crop Science, v.7, n.4, p.329-332, 1967.

CANTARUTTI, R.B.; MARTINS, C.E.; CARVALHO, M.M. et al. Pastagens. In: RIBEIRO, A.C.; GUIMARÃES, P.T.G.; ALVAREZ V.V.H. (Eds.) Comissão de Fertilidade do Solo do Estado de Minas Gerais. Recomendação para o uso de corretivos e fertilizantes em Minas Gerais. Viçosa, MG: $5^{a}$ aproximação. Viçosa, MG, 1999. p.332-341.

CARNEVALLI, R.A. Uso de metas de pasto para a realização do manejo do pastejo. In: SIMPÓSIO SOBRE MANEJO DA PASTAGEM, 25., 2009, Piracicaba. Anais... Piracicaba: FEALQ, 2009. p.59-116.

CARVALHO, P.C.F.; RIBEIRO FILHO, H.M.N.; POLI, C.H.E.C. et al. Importância da estrutura da pastagem na ingestão e seleção de dietas pelo animal em pastejo. In: REUNIÃO ANUAL DA SOCIEDADE BRASILEIRA DE ZOOTECNIA, 38., 2001, Piracicaba. Anais... Piracicaba: ESALQ, 2001. p.883-871.

CHAPIN, F.S.; BLOOM, A.J.; FIELD, C.B. et al. Plant responses to multiple environmental factors. Bioscience, v.37, n.1, p.49-57, 1987.

FAGUNDES, J.L.; FONSECA, D.M.; MISTURA, C. et al. Características morfogênicas e estruturais do capim-braquiária em pastagem adubada com nitrogênio avaliadas nas quatro estações do ano. Revista Brasileira de Zootecnia, v.35, n.1, p.21-29. 2006.

FONSECA, D.M.; SANTOS, M.E.R.; MARTUSCELLO, J.A. Adubação de pastagens no Brasil: uma análise crítica. In: SIMPÓSIO SOBRE MANEJO ESTRATÉGICO DA PASTAGEM, 4., 2008, Viçosa, MG. Anais... Viçosa, MG: UFV, 2008. p.295-334.

FREITAS, F.P. Produção e valor nutritivo do capim-tanzânia sob doses de nitrogênio e densidades de plantas. 2008, 65f. Dissertação (Mestrado em Zootecnia) - Universidade Federal de Viçosa, Viçosa, MG.

GARCEZ NETO, A.F.; NASCIMENTO JÚNIOR, D.; REGAZZI, A.J. et al. Respostas morfogênicas e estruturais de Panicum maximum cv. Mombaça sob diferentes níveis de adubação nitrogenada e alturas de corte. Revista Brasileira de Zootecnia, v.31, n.5, p.1890-1900, 2002.
GOMIDE, C.A.M.; GOMIDE, J.A. Análise de crescimento de cultivares de Panicum maximum Jacq. Revista Brasileira de Zootecnia, v.28, n.4, p.675-680, 1999.

LAMBERS, H. Does variation in photosynthesis rate explain variation in growth rate and yield? Netherlands Journal Agricultural Science, v.35, n.4, p.505-519, 1987.

LIMÃO, V.A. Padrões de crescimento de pastos de capimmulato submetidos a estratégias de pastejo rotativo. 2010, 60f. Dissertação (Mestrado em Ciência Animal) - Escola Superior de Agricultura "Luiz de Queiroz”, Piracicaba.

MARENCO, R.A.; LOPES, N.F. Fisiologia vegetal. Viçosa, MG: Editora UFV, 2009. 486p.

MARTUSCELLO, J.A.; FONSECA, D.M.; NASCIMENTO JÚNIOR, D. et al. Características morfogênicas e estruturais do capimxaraés submetido à adubação nitrogenada e desfolhação. Revista Brasileira de Zootecnia, v.34, n.5, p.1475-1482. 2005.

OLIVEIRA, M.A.; PEREIRA, O.G.; GARCIA, R. et al. Rendimento e valor nutritivo do capim-tifton 85 (Cynodon spp.) em diferentes idades de rebrota. Revista Brasileira de Zootecnia, v.29, n.6, p.1949-1960, 2000.

PACIULLO, D.S.C.; GOMIDE, J.A.; RIBEIRO, K.G. Adubação nitrogenada do capim elefante cv. Mott 1. Rendimento forrageiro e características morfogênicas ao atingir 80 e 120 cm de altura. Revista Brasileira de Zootecnia, v.27, n.6, p.1069-1075, 1998.

PARSONS, A.J.; LEAFE, E.L.; COLLET, B. et al. The physiology of grass production under grazing. II. Photosynthesis, crop growth and animal intake of continuously-grazed swards. Journal of Applied Ecology, v.20, n.1, p.127-139, 1983.

PEDREIRA, C.G.S. Gênero Cynodon. In: FONSECA, D.M.; MARTUSCELLO, J.A. (Eds.) Plantas forrageiras. Viçosa, MG: UFV, 2010. p.78-130.

PEDREIRA, C.G.S., TONATO, F. Bases ecofisiológicas para o manejo de gramíneas do gênero Cynodon. In: SIMPÓSIO SOBRE MANEJO ESTRATÉGICO DA PASTAGEM, 3., 2006, Viçosa, MG. Anais... Viçosa, MG: UFV, 2006. p.93-115.

RADFORD, P.J. Growth analysis formulae-their use and abuse. Crop Science, v.7, n.3, p.171-175, 1967.

SANTOS, M.E.R.; FONSECA, D.M.; EUCLIDES, V.P.B. et al. Características estruturais e índice de tombamento de Brachiaria decumbens cv. Basilisk em pastagens diferidas. Revista Brasileira de Zootecnia, v.38, n.4, p.626-634, 2009. 